\title{
Sasi Laut Folley dan Dinamika Pengelolaan Berbasis Masyarakat
}

\section{Sasi Laut Folley and Dynamics of Community Based Management}

Fevi Rahma Dwi Putri, Arif Satria, Saharuddin

Program Studi Sosiologi Pedesaan, Sekolah Pascasarjana, Institut Pertanian Bogor, Kampus IPB Darmaga Bogor, 16680, Indonesia [+62-251-8627793]

\section{Article Info:}

Received: 23 - 01 - 2020

Accepted: 13 - $03-2020$

\section{Keywords:}

Community based management, institution, management

dynamics, sasi laut.

Corresponding Author: Fevi Rahma Dwi Putri Program Studi Sosiologi

Pedesaan, Sekolah Pascasarjana, Institut Pertanian Bogor, fevirahmadwip16@gmail.com

\begin{abstract}
Indonesia's natural resources are decline due to excessive use of natural resources and destructive behavior without the responsibility of various parties. Community-based management (CBM) such as the management of Sasi Laut in Kampung Folley, West Papua is one of the models considered appropriate to mitigates the degradation of the natural resource in Indonesia. This study aims to analyze the dynamics of the management of Kampung Folley Sea Sasi and its impact on strengthening management. The results of this study indicate that there is a management dynamics that involves at least six momentum changes, namely the formation of the village, the intervention of the role of religion, the introduction of technology, the involvement of external parties and the establishment of regulations for Water Conservation Area. The management elements that have changed are territorial boundaries, regulations, authority holders, rights, sanctions, and monitoring due to internal and external factors. The management dynamics that occur are leading to the strengthening of Sasi Laut management.
\end{abstract}

How to cite (CSE Style $8^{\text {th }}$ Edition):

Putri FRD, Satria A, Saharuddin. 2020. Sasi laut Folley dan dinamika pengelolaan berbasis masyarakat. 10(1): 111-123. http://dx.doi.org/10.29244/jpsl.10.1. 111-123.

\section{PENDAHULUAN}

Indonesia adalah negara maritim dengan luas perairan \pm 6.315 juta $\mathrm{km}^{2}$ atau setara tiga kali luas wilayah daratan Indonesia yaitu 1913578.68 juta km² (KKP, 2015; BPS, 2018). Indonesia juga disebut sebagai negara bahari dan mega-biodieversity karena didominasi ekosistem lautan dan keanekaragaman sumber daya didalamnya (Dahuri, 2003). Teridentifikasi 6.869 jenis biota laut termasuk tumbuhan laut (mangrove, alga, dan lamun), terbagi atas $77.87 \%$ fauna, $14.14 \%$ alga, 2.08\% flora, dan 5.91\% mikroba laut (BPS, 2017). Pengelolaan potensi yang bijaksana dan terpadu seharusnya memberi manfaat optimal bagi kemajuan negara, kesejahteraan masyarakat dan kelestarian lingkungan. Realitasnya, Indonesia mengalami penurunan kualitas dan kuantitas sumber daya alam, khususnya sektor kelautan. Merujuk berita lingkungan Mongabay (2017), data Lembaga Ilmu Pengetahuan Indonesia (LIPI) (2016) menjelaskan terumbu karang Indonesia dengan kondisi baik tersisa $5.32 \%$, sementara $>30 \%$ kondisi kurang baik dari luas \pm 2.5 juta Ha. Berpengaruh pada penurunan ketersediaan biota lain, karena fungsi terumbu karang sebagai ruang hidup berbagai biota yang terikat rantai makanan (Noviana et al., 2019). Penyebab utama diungkapkan Bappenas (2014) dalam BPS (2018) adalah pengelolaan perikanan Indonesia belum optimal, kecenderungan prilaku eksploitatif manusia 
pada wilayah open acces ${ }^{l}$ seperti aktivitas Illegal, Unreported, dan Unregulated (IUU) Fishing, overfishing, belum efektifnya sistem pengawasan, dan konversi lahan tidak sesuai peruntukkannya.

Konservasi menjadi salah satu alternatif pencegahan dan penanggulangan krisis yang terjadi. Berbagai regulasi diterbitkan untuk mendorong perluasan kawasan tersebut. Realitasnya, konservasi seringkali cenderung sentralistik dan memicu perbedaan kepentingan antara masyarakat dan pemerintah. Sebagai contoh kajian Satria (2009), keputusan pemerintah menetapkan Taman Nasional Wisata Alam Laut (TWAL) telah menimbulkan konflik dengan masyarakat yang mengklaim wilayah TWAL merupakan wilayah strategis untuk penangkapan sumber daya pesisir dan laut melalui intepretasi wilayah hak ulayat masyarakat. Benturan kepentingan juga hadir antara masyarakat dan korporat seperti perusahaan yang mengubah peruntukan wilayah perikanan tangkap masyarakat menjadi sektor pariwisata atau industri.

Urgensi pengentasan krisis lingkungan yang dibutuhkan adalah pengelolaan yang menyelaraskan tujuan multipihak. Horowitz (2015) dalam memberikan kontribusi gagasan Local Environment Knowledge (LEK), sebagai respon banyaknya wacana menyalahkan penduduk lokal atas peristiwa degradasi ekologi akibat praktik lokal didasarkan pada ketidaktahuan dan tradisi yang irrasional. LEK hadir untuk membongkar dikotomi pengetahuan "lokal" dan "ilmiah", sehingga membentuk pengelolaan yang mempersatukan tujuan keduanya. Rekomendasi Ostrom (1990) terkait dua pilihan model yang dinilai lebih preventif bagi pengelolaan sumber daya adalah pengelolaan berbasis masyarakat (PBM) atau community based management (CBM) dan pengelolaan kolaboratif atau co-management. Penelitian ini fokus mengkaji PBM. Sebagaimana disinggung khusus oleh Ostrom (1990), kelembagaan masyarakat dapat menjamin berkelanjutan sumber daya, karena kecenderungan prinsip yang dianut adalah keberlanjutan. Penelitian ini menganalisis pengelolaan Sasi Laut di Kampung Folley, Distik Misool Timur, Kabupaten Raja Ampat, Provinsi Papua Barat.

Sasi Laut adalah kelembagaan tradisional yang menerapkan prinsip konservasi, yaitu mengatur tentang masa pemeliharaan dan panen teripang, batulaga, lola dan lainnya dalam jangka waktu tertentu. Menurut Sztompka (2004), tradisi merupakan segala sesuatu (meliputi adat, kepercayaan, kebiasaan, ajaran dan lainnya) yang berlangsung secara turun temurun dan melekat dalam kehidupan. Proses konstruksi sosial secara berkala, menjadikan Sasi Laut berkembang dan mengalami perubahan baik menguatkan atau melemahkan sebagaimana dinamika sosial. Berita lingkungan Mongabay, 12 Juli 2015 memaparkan Sasi Laut Folley adalah salah satu kearifan lokal yang masih bertahan, bahkan mengalami peningkatan produksi, pendapatan dan penyokong pembangunan kampung. Diduga dinamika pengelolaan Sasi Laut Folley mengarah pada penguatan pengelolaan. Oleh karena itu, tujuan penelitian ini untuk menganalisis dinamika pengelolaan Sasi Laut Folley sebagai PBM serta pengaruhnya terhadap penguatan pengelolaan.

\section{METODE}

\section{Lokasi dan Waktu Penelitian}

Penelitian dilaksanakan di Kampung Folley, Distrik Misool Timur, Kabupaten Raja Ampat, Provinsi Papua Barat. Penelitian dilakukan pada bulan September 2018 - April 2019.

\section{Metode Pengumpulan Data}

Penelitian bertujuan mengkaji dinamika pengelolaan berbasis masyarakat menggunakan paradigma konstruktivis dan metode penelitian kualiatatif. Paradigma konstruktivis berusaha memahami realitas sosial dengan mengembangkan makna-makna subjektif atas pengalaman individu pada objek kajian (Creswell 2016). Pengumpulan data kualitatif menitikberatkan kepada interaksi peneliti dan tineliti, karena persepsi, pandangan dan pemahaman tineliti didalami melalui proses tersebut. Strategi penelitian adalah studi kasus. yaitu mengarahkan peneliti untuk mengembangkan analisis mendalam suatu kasus, seperti program, peristiwa,

\footnotetext{
${ }^{1}$ Tidak berlaku hak kepemilikan sumber daya atau bersifat bebas diakses siapapun tanpa regulasi pemanfaatan (Bromley, 1992). Wahyuningsih et al. (2019) memaknai status open acces ketika tidak seimbangnya laju pemanfaatan dan laju pemulihan sumberdaya. 112
} 
aktivitas atau proses, dengan berbagai prosedur pengumpulan data berdasarkan waktu yang ditentukan (Stake 1995 dan Yin 2009, 2012 dalam Creswell, 2016).

Subjek penelitian adalah informan yang dipilih secara sengaja, yaitu individu atau kelompok yang dianggap memahami dan berkaitan dengan pengelolaan Sasi Laut. Populasi penelitian adalah masyarakat pelaksana kelembagaan Sasi Laut di Kampung Folley. Unit analisis adalah komunitas pelaksana kelembagaan. Informan terpilih yaitu pemerintah Kabupaten Raja Ampat, pemerintah Distrik Misool Timur, Pemerintah Kampung Folley, tokoh adat dan agama, anggota marga pemilik wilayah adat, kelompok masyarakat terkait, Pihak Unit Pelaksana Teknis Kawasan Konservasi Perairan (UPT KKP), LSM The Nature Conservancy (TNC), masyarakat Matbat dan pendatang.

Data yang digunakan adalah data primer dan data sekunder (Sugiyono 2013). Data primer adalah sumber data yang langsung didapatkan oleh peneliti dari hasil observasi (pengamatan), wawancara mendalam (indepth interview), dan Focus Group Discussion (FGD). Data sekunder diperoleh dari dokumen yang berkaitan dengan penelitian, seperti dokumen di kantor pemerintahan, data kawasan konservasi dan pengelolaan Sasi Laut Raja Ampat dari kantor LSM dan Unit Pelayanan Teknis Kawasan Konservasi Perairan (UPT KKP), dokumen penunjang kekayaan teori, regulasi dan fakta empiris dari dokumen cetak dan elektronik, seperti data Badan Pusat Statistik (BPS), laporan akhir dan jurnal penelitian.

Alat yang digunakan saat wawancara mendalam yaitu panduan pertanyaan mengacu parameter yang ditentukan melalui kajian literatur. Analisis perkembangan pengelolaan berbasis masyarakat (PBM) berdasarkan parameter Ruddle (1999) terkait unsur-unsur pengelolaan yaitu batas wilayah, aturan, hak, pemegang otoritas, sanksi, pemantauan dan evaluasi. Faktor-faktor internal dan eksternal yang mempengaruhi disintesis dari kajian teoritis dan fakta empiris tulisan Berkes (2000), Alkausar (2011), Khoirunnisak dan Satria (2016). Faktor internal merupakan faktor di dalam masyarakat, berupa; 1) sejarah pengelolaan lokal; 2) pengaruh kepemimpin dan sosialisasi hukum adat; dan 3) kompleksitas masyarakat yang terdiri dari perkembangan livelihood dan identitas etnik, agama, dan perbedaan kepentingan/kebutuhan pribadi. Faktor eksternal merupakan faktor pendorong pelaksanaan di luar masyarakat yaitu; 1) dimensi regulatif; 2) intervensi multipihak; dan 3) globalisasi.

\section{Metode Analisis Data}

Data yang diperoleh berupa catatan harian, dokumen, gambar, dan audio-visual, dianalisis dengan tiga alur kegiatan bersamaan yaitu reduksi, penyajian, dan penarikan kesimpulan atau verifikasi data. Pertama, tahap reduksi yaitu mengelompokan data menjadi kelompok-kelompok catatan kategori sesuai tujuan penelitian. Kedua, tahap penyajian yaitu menyusun informasi dan data yang dikelompokkan menjadi rangkaian kata-kata, bagan, gambar dan tabel. Terakhir, tahap penarikan kesimpulan dari hasil pengolahan data dan dapat dilakukan verifikasi lapangan (Miles dan Huberman, 1992 dalam Idrus, 2009). Ketiganya merupakan kegiatan yang jalin-menjalin dilakukan saat sebelum, selama, dan sesudah pengumpulan data.

\section{HASIL DAN PEMBAHASAN}

\section{Sasi Laut Folley: Pengelolaan berbasis Masyarakat (PBM)}

Sasi merupakan sebuah kelembagaan adat di Maluku hingga Papua yang diterapkan untuk mengatur proses pemanfaatan sumber daya (Soekanto 2002). Terdapat dua macam Sasi yaitu Sasi Darat dan Sasi Laut. Penelitian ini fokus mengkaji Sasi Laut di Kampung Folley. Masyarakat adat mengatur pemanfaatan biota laut seperti teripang (holothuria scabra, holothuria nobilis, holothuria fuskogilfa, dan thelenota ananas dan bohadschia argus), kerang batu laga, siput lola, dan lainnya dengan sistem jangka waktu. Dilarang ditangkap saat masa pemeliharaan (Tutup Sasi) dan dimanfaatkan bersama saat masa panen (Buka Sasi). Alat tangkap dan teknis penangkapan juga diatur agar memenuhi standar keberlanjutan. Cooley (1987) menjelaskan Sasi menerapkan aturan dan sanksi adat yang membudaya dan diputuskan oleh para elit setempat. 
Bagi masyarakat, Sasi sebagai bentuk menabung sumber daya alam untuk dipanen diwaktu yang tepat. Selain produktivitas maksimal (berukuran besar/dewasa) dan memberikan keuntungan finansial, nilai utama Sasi adalah agar sumber daya dapat terus menjamin kehidupan generasi mendatang. Kebutuhan praktik Sasi semakin kuat karena peningkatan krisis sumber daya dan lingkungan. Sebagai contoh, pengaruh perkembangan teknologi meningkatkan eksploitasi sumber daya dan illegal fishing yang merusak. Oleh karena itu, Sasi merupakan bentuk konservasi berbasis masyarakat. Satria (2009) menjelaskan masyarakat Maluku dan Papua memiliki bentuk konservasinya sendiri atau konservasi konstruktivis.

Merujuk analisis property right, Ostrom et al. (1994) menjelaskan tingkat kekuasaan manusia memanfaatkan sumber daya berdasarkan tingkat subtractability dan excludability. Subtractability merupakan asumsi ketika sumber daya diklaim milik pribadi/kelompok, maka peluang orang lain mengambil manfaat semakin menurun. Excludability mengasumsikan kemampuan individu melarang orang lain memanfaatkan suatu sumber daya. Wilayah Sasi Laut Folley termasuk tipe common-pool resources berdasarkan teori Ostrom et al. (1994) yaitu sumber daya dimiliki bersama oleh sekelompok masyarakat dengan tingkat subtractability tinggi tetapi excludabilty rendah. Relevan dengan rezim kepemilikan oleh Bromley (1992), wilayah Sasi Laut Folley termasuk rezim common property yaitu dikuasai sekelompok masyarakat. Hak kepemilikan tidak bersifat ekslusif, keputusan dibuat bersama untuk kesejahteraan anggota dan keberlanjutan sumber daya. Ulasan diatas membuktikan Sasi Laut Folley termasuk kategori PBM, relevan dengan definisi Gorris (2016), PBM adalah pengelolaan sumber daya milik bersama menerapkan penatagunaan secara informal berdasarkan pengetahuan lokal/tradisional. Analisis pengelolaan PBM menggunakan enam unsur pengelolaan menurut Ruddle (1999) untuk melihat apakah kelembagaan Sasi Laut dapat memenuhi standar PBM.

\section{Batas Wilayah}

Secara turun-temurun, masyarakat telah mengetahui pembagian wilayah adat di Pulau Misool, terutama di Kampung sendiri. Marga Fadimpo dan Moom yang diakui memiliki hak ulayat laut di Kampung Folley, sehingga kedua marga melaksankan kelembagaan Sasi Laut. Luas wilayah adat Marga Fadimpo yaitu dari jembatan dermaga depan kampung kearah timur sepanjang \pm 2.5 , dan Marga Moom sepanjang $\pm 1 \mathrm{~km}$ kearah barat. Batas wilayah Sasi Laut diperjelas dengan batas-batas alam. Marga Fadimpo dari Tanjung Vagita, hingga ke Kali Mebel, sedangkan Marga Moom dari jembatan dermaga hingga Teluk Nukari. Pelibatan peran agama kristiani sejak tahun 1976 berkontribusi menambah kejelasan batas wilayah melalui simbol keagamaan, yaitu penancapan papan "Sasi Gereja" di beberapa titik kawasan Sasi.

Sasi Laut termasuk dalam Kawasan Konservasi berdasarkan ketetapan Perbub No 66 tahun 2007 tentang Kawasan Konservasi Laut Daerah (KKLD) Kab. Raja Ampat (kini Kawasan Konservasi Perairan Daerah/KKPD) hingga dikeluarkannya Kepmen KP RI No 36/Kepmen-KP 2014 tentang rencana pengelolaan Kawasan Konservasi Perairan Kepulauan Raja Ampat yang melampirkan Peta Zonasi Jejaring Kawasan Konservasi Perairan Kabupaten Raja Ampat, Provinsi Papua Barat. Wilayah Sasi Laut Folley termasuk dalam Subzona Sasi dan Pemanfaatan Tradisional Masyarakat (Gambar 1).

\section{Hak Kepemilikan}

Merujuk analisis kesatuan hak (bundle of rights), terdapat lima status kepemilikan berdasarkan hak ${ }^{2}$ yang dimiliki aktor, antara lain authorized entrant, merupakan pihak yang hanya memiliki hak akses. Kedua, authorized user yaitu memiliki hak akses dan hak pemanfaatan. Ketiga, claimant, memiliki hak akses, hak pemanfaatan dan hak pengelolaan. Keempat, propriertor, memiliki hak akses, hak pemanfaatan, hak

\footnotetext{
${ }^{2}$ Ostrom dan Schlager (1996) menguraikan lima tipe hak, yaitu; 1) Hak akses (access right), hak untuk masuk ke wilayah sumber daya, 2) Hak pemanfaatan (withdrawl right), hak untuk memanfaatkan sumber daya atau hak berproduksi; 3) Hak pengelolaan (management right), hak menentukan aturan operasional pemanfaatan sumber daya; 4) Hak eksklusi (exclussion right), hak menentukan pihak mana yang diperbolehkan untuk mengakses; 5) Hak pengalihan (alienation right), hak untuk menjual atau menyewakan sumber daya.
}

114 
pengelolaan hingga hak ekslusi. Kelima, owner, pihak yang memiliki seluruh hak termasuk hak pengalihan. Tabel 1 menjelaskan tipe hak dan status kepemilikan sumber daya alam.

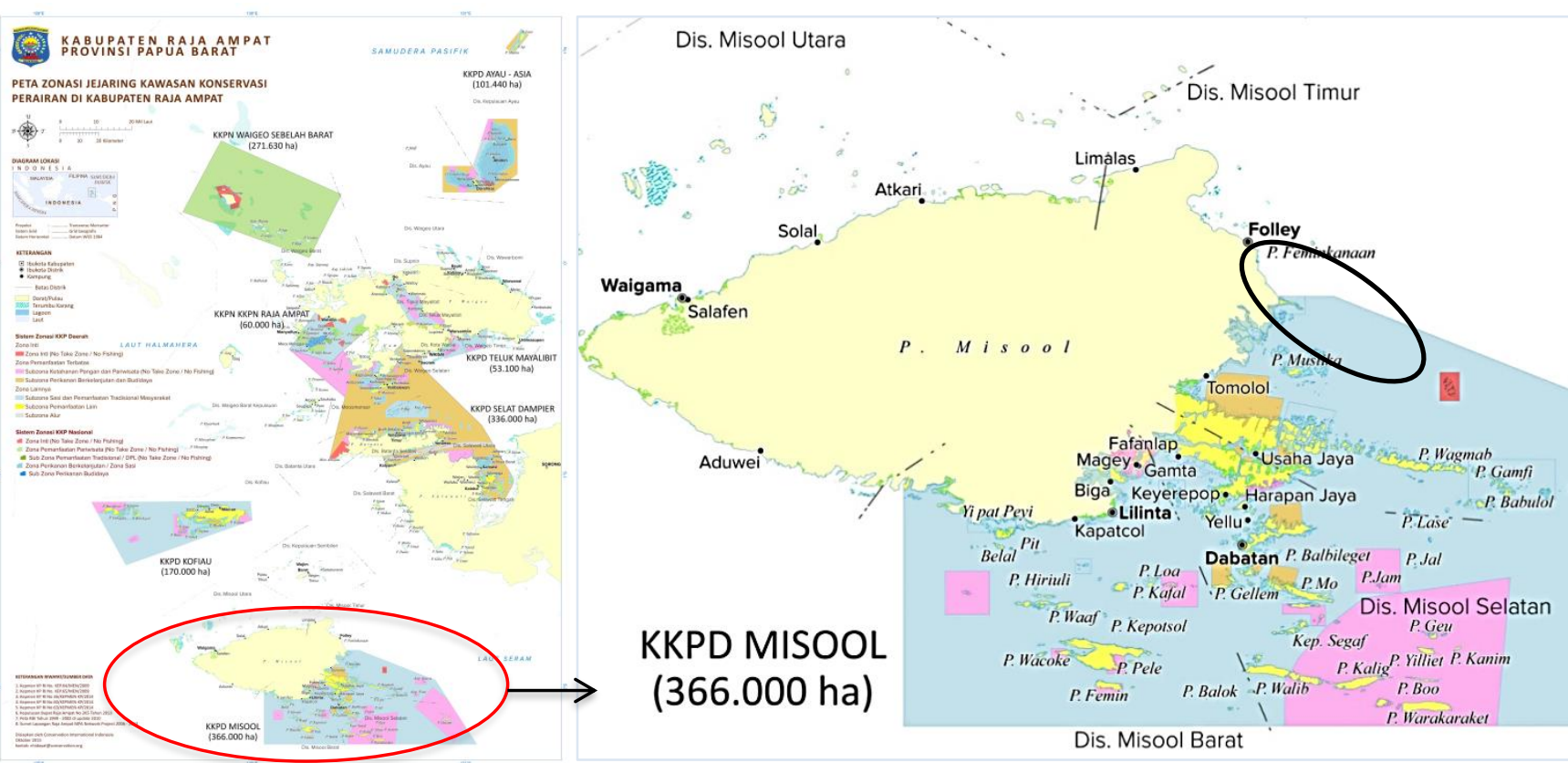

Gambar 1 Peta Zonasi Jejaring Kawasan Konservasi Perairan Kabupaten Raja Ampat, Provinsi Papua Barat.

Keterangan: $\quad$ : Subzona Sasi dan Pemanfaatan Tradisional

: Kawasan Sasi Laut Folley

Tabel 1 Tipe Hak dan Status Kepemilikan Sumber Daya menurut Ostrom dan Schalager (1996).

\begin{tabular}{lccccc}
\hline \multirow{2}{*}{ Tipe Hak } & \multicolumn{5}{c}{ Status } \\
\cline { 2 - 6 } & Owner & Proprieter & Claimant & Authorized User & $\begin{array}{c}\text { Authorized } \\
\text { Entrant }\end{array}$ \\
\hline Akses & $\mathrm{X}$ & $\mathrm{X}$ & $\mathrm{X}$ & $\mathrm{X}$ & $\mathrm{X}$ \\
Pemanfaatan & $\mathrm{X}$ & $\mathrm{X}$ & $\mathrm{X}$ & $\mathrm{X}$ & \\
Pengelolaan & $\mathrm{X}$ & $\mathrm{X}$ & $\mathrm{X}$ & & \\
Eksklusi & $\mathrm{X}$ & $\mathrm{X}$ & & \\
Pengalihan & $\mathrm{X}$ & & & \\
\hline
\end{tabular}

Analisa hak kepemilikan sumber daya di Kabupaten Raja Ampat sebagian besar akan memberikan dua sudut pandang, yaitu secara de facto dan de jure. Hak kepemilikan wilayah Sasi Laut Marga Fadimpo dan Moom atas dasar pengetahuan lokal dan ketetapan adat (de facto) adalah sebagai propriertor. Masyarakat memiliki hak akses, pemanfaatan, pengelolaan hingga ekslusi atau menentukan peruntukan kawasan dan membatasi pihak lain memanfaatkan sumber daya saat Tutup Sasi. Masyarakat di luar marga tersebut baik dalam maupun luar kampung diperbolehkan melewati kawasan dan memanfaatkan hasil Sasi Laut. Kelompok ini berstatus authorized user. Secara de jure melalui kebijakan KKPD, pemerintah mengakui wilayah adat masyarakat dan memberikan kewenangan sah bagi masyarakat untuk mengelola kawasan tersebut. Status yang dimiliki masyarakat secara formal bagi negara adalah claimant.

Pemegang Otoritas 
Menurut masyarakat, kelembagaan Sasi Laut merupakan kearifan lokal yang telah terbentuk jauh sebelum pemerintahan Raja Ampat berdiri. Tokoh adat sebagai pemimpin dan pembina masyarakat sejak dulu, dipercaya menjadi pemegang otoritas kelembagaan Sasi. Era kini, aktor-aktor lain mulai dilibatkan dalam pengelolaan mengikuti perkembangan zaman. Masyarakat menyebutnya sebagai tiga tungku tak terpisah, yaitu tokoh adat, tokoh agama dan pemerintah. Tabel 1 memetakan aktor-aktor dan peranannya terhadap pengelolaan Sasi Laut.

Tabel 2 Pemetaan Aktor dan Peranan.

\begin{tabular}{|c|c|c|}
\hline Kategori & Aktor/Kelompok & Peranan \\
\hline Adat & Tokoh Adat & Penginisiasi, pengambil keputusan, dan pemimpin upacara adat \\
\hline \multirow[t]{2}{*}{ Agama } & Pendeta, Majelis & $\begin{array}{l}\text { Memberikan saran, melaksanakan prosesi doa gereja, penancapan } \\
\text { papan sasi dan mengatur pajak persepuluhan }\end{array}$ \\
\hline & Pemuda Gereja & $\begin{array}{l}\text { Mambantu kegiatan monitoring, acara Tutup dan Buka Sasi, } \\
\text { memanen hasil untuk keperluan bersama. }\end{array}$ \\
\hline \multirow[t]{4}{*}{ Pemerintah } & $\begin{array}{l}\text { Pemerintah } \\
\text { Kampung }\end{array}$ & $\begin{array}{l}\text { Memberi saran, menghadiri acara adat, penghubung pihak eksternal, } \\
\text { penugasan Babinsa Hansip untuk pengawasan. }\end{array}$ \\
\hline & $\begin{array}{l}\text { Pemerintah } \\
\text { Distrik }\end{array}$ & $\begin{array}{l}\text { Menghadiri upacara adat, penghubung pihak eksternal seperti Pemda, } \\
\text { Pusat, serta pihak media promosi. }\end{array}$ \\
\hline & $\begin{array}{l}\text { Pemerintah } \\
\text { Daerah dan Pusat }\end{array}$ & $\begin{array}{l}\text { Menghadiri upacara adat, menugaskan UPT KKP dan LSM TNC } \\
\text { untuk pendampingan, mengakui kawasan Sasi Laut dalam KKPD }\end{array}$ \\
\hline & UPT KKP & Monitoring kawasan KKPD \\
\hline \multirow[t]{2}{*}{ LSM } & TNC & $\begin{array}{l}\text { Mendampingi masyarakat dengan memberikan edukasi keberlanjutan } \\
\text { lingkungan, pengetahuan penunjang hasil Sasi, meningkatkan } \\
\text { keberdayaan masyarakat, meningkatkan publikasi. }\end{array}$ \\
\hline & $\begin{array}{l}\text { Fasilitator } \\
\text { Kampung }\end{array}$ & $\begin{array}{l}\text { Monitoring, perantara masyarakat dan LSM, fasilitator kegiatan } \\
\text { pendidikan lingkungan termasuk Sasi Laut }\end{array}$ \\
\hline Masyarakat & $\begin{array}{l}\text { Lokal dan } \\
\text { pendatang }\end{array}$ & Mengakui, mematuhi, dan mengawasi pelaksanaan Sasi Laut \\
\hline
\end{tabular}

\section{Peraturan}

Peraturan kelembagaan Sasi Laut terus berkembang mengikuti perkembangan zaman. Peraturan yang ditetapkan dalam praktik Sasi Laut Folley kini adalah sebagai berikut:

1. Penentuan waktu Tutup dan Buka Sasi didasarkan berbagai pertimbangan, seperti ditutup selama satu musim/tahun, dibuka saat hari raya atau peristiwa genting misalnya masa masuk sekolah, pembangunan fasilitas umum, memperhitungkan jumlah serta ukuran biota siap dipanen melalui hasil monitoring.

2. Dilarang mengambil biota-biota laut yang sepakat di Sasi dalam jangka waktu yang ditentukan.

3. Pada saat Buka Sasi, masyarakat dilarang berjalan kaki dan memanen hasil dengan tangan kosong. Diwajibkan memakai perahu dan penikam agar tidak merusak karang dan mendapatkan hasil merata.

4. Dilarang menggunakan peralatan merusak, seperti bom dan kompresor baik saat Tutup atau Buka Sasi.

5. Setiap pihak tanpa terkecuali diperbolehkan mengambil hasil saat Buka Sasi, namun dibebankan persepuluhan (pajak amalan 10\%) yang akan dipersembahkan untuk gereja. Ini merupakan kepercayaan kaum kristiani tentang kewajiban umat memberikan $10 \%$ dari penghasilannya pada gereja.

6. Memberlakukan biaya Rp 100,000 di wilayah adat Moom, dan Rp 200,000 di wilayah Fadimpo bagi perahu pemanen. Pembayaran hanya satu kali untuk Buka Sasi (biasanya 2 minggu). Pajak tersebut dipergunakan untuk kepentingan umum, seperti pembangunan gereja, kegiatan agama, dan lainnya.

\section{Sanksi}


Terdapat berbagai golongan sanksi yaitu sanksi adat, agama, sosial, ekonomi, fisik dan formal. Semula sanksi yang berlaku hanya sanksi adat dan sosial. Masyarakat percaya bahwa keberadaan leluhur dapat melindungi kawasan Sasi Laut. Tidak sedikit kasus pelanggaran berdampak buruk pada kesehatan seperti buta, lumpuh, hingga meninggal. Hukuman ini dipercaya datang dari para leluhur karena diluar kendali manusia. Sanksi sosial berupa pelabelan negatif, seperti masyarakat Kampung Wejim, Distrik Kepulauan Sembilan dipandang sebagai kampung pencuri karena banyaknya pelanggaran pada Sasi Laut Folley.

Saat ini telah berlaku sanksi agama, ekonomi, fisik dan seharusnya formal. Hukuman yang irrasional dipercaya juga hadir dari Tuhan. Ketika pihak UPT KKP sedang patroli dan menemukan pelanggaran di wilayah Sasi Laut, maka hanya dikenakan sanksi fisik (push up, mengangkat beban berat memutari lapangan) dan penyitaan peralatan oleh pihak berwenang seperti Babinsa, UPT KKP, Hansip, dan Kepolisian (sanksi ekonomi). Proses hukum positif yang berlaku terhadap pelanggaran Sasi belum pernah dilakukan karena beberapa alasan, yaitu belum terdapat petunjuk teknis dan disposisi khusus terkait pengawasan dan sanksi kawasan Sasi Laut, serta keterbatasan akses transportasi menuju pusat pemerintahan untuk memproses pelanggaran.

\section{Monitoring dan Evaluasi}

Kegiatan monitoring dilakukan rutin oleh kelompok pemuda gereja/pemuda Sasi, fasilitator kampung dan didampingi oleh LSM TNC. Meskipun ketetapan waktu Tutup Sasi sudah disepakati, namun melalui monitoring dapat terlihat hasil Sasi telah mencapai standard siap panen atau sebaliknya. Ada kemungkinan penundaan proses Buka Sasi hingga menunggu teripang siap dipanen. Evaluasi dilaksanakan setelah praktik Buka Sasi selesai dilakukan (biasanya 2 (dua) minggu). Proses evaluasi dilakukan secara bersamaan dengan kegiatan perencanaan Tutup Sasi selanjutnya. Bahan evaluasi berupa pengalaman dari proses Tutup dan Buka Sasi sebelumnya yang menjadi rekomendasi perbaikan bagi pelaksanaan periode selanjutnya.

\section{Dinamika Pengelolaan Sasi Laut di Kampung Folley, Kab. Raja Ampat, Papua Barat}

Novaczek et al. (2001) yang dikutip Pical (2008) menyatakan Sasi sebagai suatu kelembagaan tidak bersifat statis, namun mengalami perubahan dari waktu ke waktu. Kelembagaan sendiri didefinisikan sebagai nilai-nilai dan norma-norma yang membentuk seperangkat pengaturan masyarakat dalam mengatur prilaku hidup tertib masyarakat terutama dalam proses pemenuhan kebutuhannya. Tulisan ini menguraikan analisis dinamika pengelolaan Sasi Laut Folley berupa perubahan unsur pengelolaan dalam beberapa periode waktu melalui pengkajian momentum-momentum perubahan penting masyarakat, sehingga mendapatkan data komprehensif. Faktor internal dan eksternal yang mempengaruhi menggunakan parameter yang disintesis dari Berkes (2000), Alkausar (2011), Khoirunnisak dan Satria (2016).

Momentum perubahan di Kampung Folley berkaitan dengan perkembangan pembangunan dan kompleksitas masyarakat yang berpengaruh terhadap pengelolaan Sasi Laut hingga kini yang dapat dibagi menjadi enam periode. Pertama, Kampung Folley dibangun tahun 1972 setelah migrasi penduduk dari Tanjung Vagita dan Pulau Holl. Masyarakat asli Suku Matbat dan pendatang dari Buton bekerjasama membangun Kampung dalam semua aspek. Sasi Laut masa ini telah dilaksanakan oleh Marga Fadimpo Suku Matbat dan masih murni berdasarkan pengetahuan adat yang diturunkan nenek moyang. Faktor internal berperan dalam masa ini, yaitu sejarah pengelolaan lokal, pengaruh pemimpin dan hukum adat, serta homogenitas.

Kedua, mayoritas masyarakat telah menganut agama dan Suku Matbat beragama kristiani. Tahun 1976, dibangun gereja pertama yang memperkokoh keimanan, karena ibadah menjadi rutin dan semua kegiatan melibatkan peran agama, termasuk Sasi. Masyarakat percaya tidak hanya leluhur yang menjaga keselamatan masyarakat dan sumber dayanya, namun Tuhan sang pencipta. Oleh karena itu, peran adat dan agama mulai berdamping dalam praktik Sasi Laut, diantaranya; 1) menambah prosesi berdoa bersama dipimpin 
pendeta/majenlis pada ibadah besar minggu; 2) ketentuan persepuluhan, dan; 3) pelibatan panitia gereja. Dapat dianalisis faktor yang mempengaruhi adalah kompleksitas keyakinan masyarakat (adat dan agama).

Ketiga, tahun 1980an merupakan momentum semakin kompleksnya masyarakat. Perpindahan penduduk mulai meningkat akibat faktor perkawinan, pekerjaan dan intervensi program pemerintah yaitu perkebunan, pembangunan sekolah, dan sebagainya. Keberagaman identitas masyarakat meningkat, seperti bertambahnya tiga marga dari suku Matbat, yaitu Marga Faloy, Marga Mjam, dan Marga Mlui yang mayoritas karena perkawinan. Program internalisasi perkebunan dari pemerintah daerah tahun 1982, banyak membawa pekerja dari Maluku, Jawa, dan Bugis. Realitasnya, momentum ini tidak berpengaruh signifikan terhadap perubahan pengelolaan Sasi Laut. Pendatang tidak dilibatkan dalam pengelolaan, namun diperbolehkan ikut memanfaatkan hasil saat Buka Sasi. Disamping itu, mayoritas pendatang dari luar Papua bertujuan untuk bekerja formal atau memilih bercocok tanam memanfaatkan daratan rendah Kampung Folley yang luas dan subur. Keterbatasan skill dan sarana melaut juga membatasi pendatang tidak melakukan kegiatan di laut, sehingga praktik Sasi Laut tidak menjadi penghalang bagi pendatang mencari nafkah.

Keempat, tahun 1991 momentum diresmikan Kampung Folley sebagai desa administratif. Pemerintah bertanggung jawab terhadap seluruh kegiatan masyarakat, meskipun pada pengelolaan Sasi tidak berwenang sebagai pengambil keputusan. Peran pemerintah yaitu menyetujui, menghadiri dan mengawasi pelaksanaan, serta penghubung pihak eksternal (pemerintah daerah, pusat dan pembeli hasil). Transformasi kampung terpencil menjadi desa membuka jalan pengembangan teknologi, seperti mesin listrik, mesin kapal, lampu penerang, dan berbagai alat tangkap. Teknologi dapat memudahkan aktivitas masyarakat, namun di sisi lain beberapa pihak melakukan kegiatan perikanan tangkap merusak seperti pemboman liar. Pengembangan peraturan dilakukan masyarakat untuk memanfaatkan intervensi teknologi sekaligus meminimalisir kerusakan. Pemanen Sasi Laut dilarang mengambil biota dengan tangan dan berjalan kaki diatas karang, wajib mengendarai perahu dan alat penikam untuk mengurangi kerusakan karang dan distribusi hasil merata.

Kelima, tahun 2001 menjadi momentum perubahan yang signfikan pengelolaan Sasi karena faktor intervensi pihak eksternal yang bertujuan memperluas pendidikan lingkungan. LSM TNC hadir melakukan pendampingan masyarakat hingga saat ini. TNC membentuk fasilitator kampung yang dilatih menjadi pelopor kegiatan pelestarian lingkungan, inovasi pertanian dan perikanan, hingga membantu pengelolaan Sasi Laut mulai tahun 2010. TNC memberikan pengetahuan ilmiah yang menunjang produktivitas Sasi Laut dan dapat membuat pengetahuan lokal dan ilmiah diaplikasikan bersamaan. Masa ini mengubah unsur batas wilayah, peraturan dan monitoring. Sebelumnya, hanya marga Fadimpo yang melaksanakan kegiatan Sasi. Mulai tahun 2012, Marga Moom turut melaksanakan Sasi Laut di wilayah adatnya karena terpacu dengan peningkatan signifikan hasil produksi Sasi Laut marga Fadimpo, serta kebutuhan revitalisasi wilayah. Pada unsur peraturan, TNC menyarankan batas ukuran minimal teripang mencapai $15 \mathrm{~cm}$ (teripang dewasa) untuk mengurangi resiko kegagalan Buka Sasi periode berikutnya dan kepunahan sumber daya. TNC juga memfasilitasi kebutuhan sarana monitoring dan melaksanakan monitoring rutin bersama masyarakat.

Terakhir, tahun 2006-2014 perubahan dilatarbelakangi faktor eksternal dimensi regulasi dan pengakuan formal, yaitu momentum penetapan KKPD di Raja Ampat. UPT KKP dibentuk untuk mengelola program dan keuangan KKPD. Salah satu kegiatan utama adalah melakukan patroli kawasan, termasuk kawasan Sasi. Bantuan monitoring yang dilakukan sedikit membantu masyarakat meminimalisir pelanggaran. Pengakuan yang sah kawasan Sasi di ranah hukum, memperlebar pemberlakuan sanksi yaitu sanksi ekonomi, fisik dan bisa masuk ke sanksi formal. Dua periode terakhir memberikan dampak cukup signifikan terhadap hasil produksi. Unsur yang paling berpengaruh yaitu monitoring kawasan dan penambahan pemberlakuan sanksi yang meminimalisir pelanggaran Sasi. Gambar 2 menunjukan produktivitas teripang hasil penerapan Sasi Laut Folley dari tahun 2003-2017. 


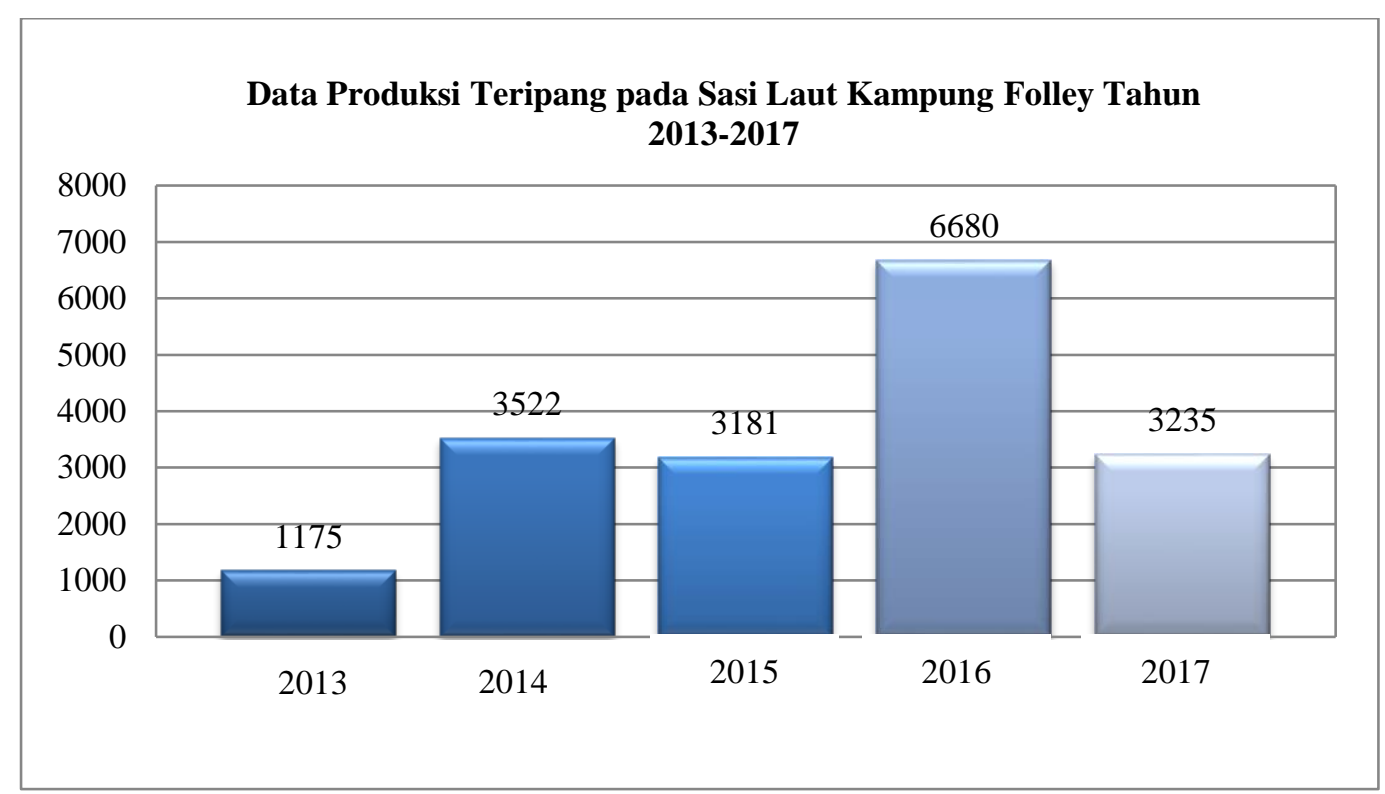

Gambar 2 Data Produktivitas Teripang Hasil Penerapan Sasi Laut di Kampung Folley tahun 2013-2017 menurut Laporan TNC (2017).

Data grafik diatas menunjukan adanya kecenderungan peningkatan produksi teripang dari tahun 20132017. Peleburan ilmu pengetahuan ilmiah dan lokal setelah masuknya pendampingan TNC, seperti Buka Sasi dilakukan mempertimbangkan hasil produksi maksimal, rata-rata ukuran teripang mencapai $15 \mathrm{~cm}$. Bantuan fasilitas monitoring dari TNC dan UPT KKP serta sanksi fisik dan ekonomi bagi pelanggar oleh pihak berwenang. Pada tahun 2017, produktivitas mengalami penurunan akibat intensitas monitoring mulai menurun. Masyarakat cenderung bergantung pada bantuan sarana monitoring pihak eksternal. Diperlukan peningkatan kemandirian masyarakat pada unsur ini agar produksi Sasi Laut tetap stabil meskipun pendampingan telah selesai dilaksanakan. Pengelolaan keuangan hasil pajak Buka Sasi sebagian dapat dianggarkan untuk kegiatan monitoring. Gambar 3 menjelaskan secara ringkas perubahan unsur-unsur pengelolaan serta faktor-faktor yang mempengaruhi perubahan berdasarkan momentum-momentum penting dalam masyarakat.

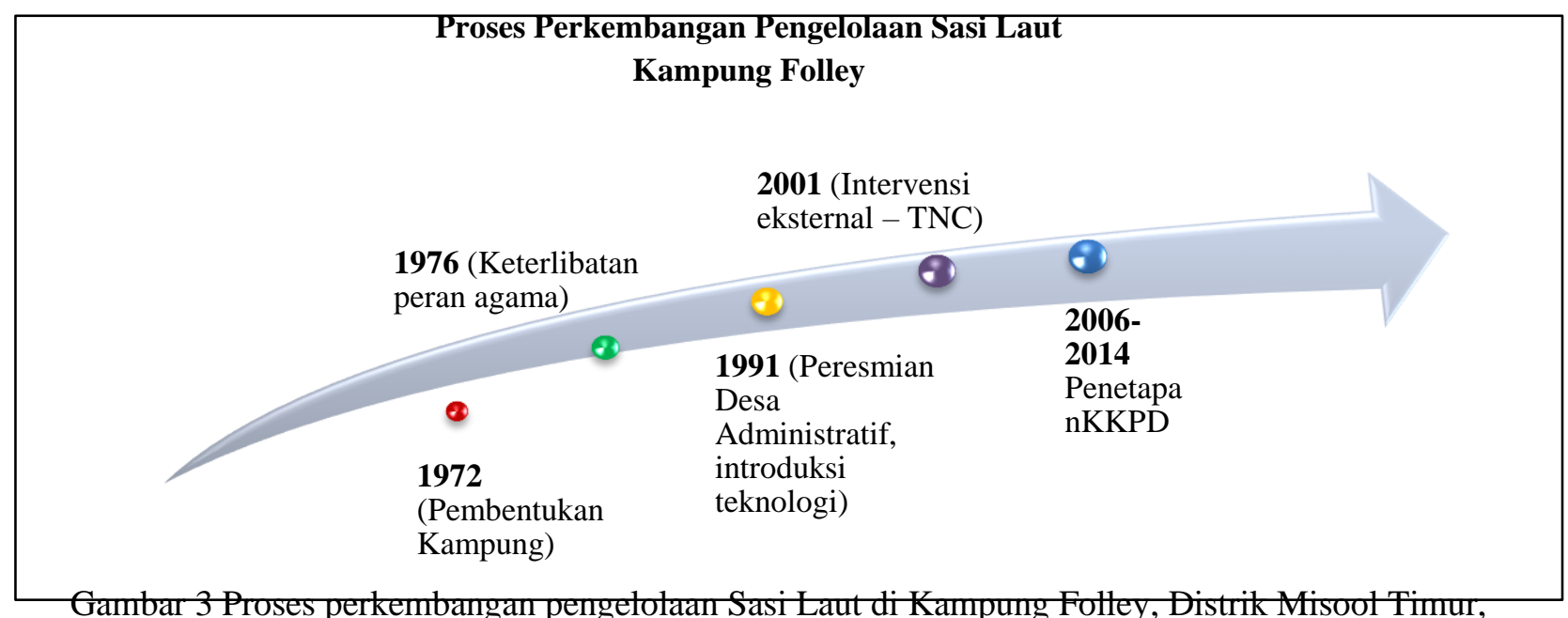

Kabupaten Raja Ampat, Provinsi Papua Barat. 
Keterangan Perubahan:

$\theta$ Murni pengetahuan adat.

Faktor : sejarah pengelolaan lokal, pengaruh pemimpin dan hukum adat, serta homogenitas.

○ Unsur : otoritas pelibatan tokoh agama, peraturan persepuluhan, sanksi agama.

Faktor : kompleksitas masyarakat.

O Unsur : otoritas Pemerintah Kampung, peraturan alat dan teknik memanen.

Faktor : dimensi regulatif dan globalisasi

Unsur : otoritas TNC, perluasan wilayah, peraturan waktu dan ukuran biota, peningkatan monitoring. Faktor : intervensi multi pihak

Unsur : otoritas pihak berwenang, monitoring UPT KKP, sanksi (fisik, ekonomi), hak Claimant.

Faktor : Dimensi regulatif dan pengakuan formal

Gambar 3 menunjukan hanya lima momentum perubahan yang berkenaan langsung dengan dinamika pengelolaan Sasi Laut. Masuknya pendatang tidak berpengaruh secara signifikan terhadap pengelolaan. Masyarakat lokal dan pendatang saling menghargai dan tidak merugikan satu sama lain.

\section{Penguatan Pengelolaan Sasi Laut Folley}

Proses perubahan pengelolaan Sasi Laut dalam setiap periode memiliki dua kemungkinan yaitu kemajuan atau kemunduran. Analisis sekunder beberapa kasus menunjukan hal tersebut, sebagai contoh penetapan regulasi pengakuan formal bagi sumber daya milik adat sangat diperlukan untuk mencapai keadilan distribusi (distributive justice) dan keadilan pengakuan (justice of recognation) agar terhindar dari berbagai gangguan eksternal merugikan. Tanpa adanya pengakuan hak tradisional resmi, masyarakat lambat laun bisa termarjinalisasi dari wilayah adatnya (Satria, 2009). Kasus lain menunjukan sisi berbeda, merujuk Satria (2009) sepanjang rezim sentralisme, pemerintah memiliki kekuasaan mutlak mengatur pengelolaan. Tak jarang sumber daya dikelola dengan tujuan pragmatis menjaga pelestarian lingkungan, dan menciptakan penerimaan bagi negara, namun kurang memperhatikan bagian masyarakat.

Masa awal pengelolaan Sasi yang dibatasi pada awal pembentukan Kampung tahun 1972 menghimpun masyarakat yang homogen. Mayoritas Suku Matbat yang memegang erat budaya Sasi sejak dulu. Sosok pemimpin yang terus menginisiasi penerapan Sasi, menjadikan Sasi tidak ditinggalkan meskipun masyarakat pindah dari satu wilayah ke wilayah lain. Masa perkembangan pendidikan dan fasilitas agama menyebabkan internalisasi peran agama dalam pengelolaan. Penambahan doa dan sanksi agama menjadikan masyarakat semakin patuh terhadap aturan Sasi, artinya intervensi agama memperkuat pengelolaan. Namun, meski sedikit juga berpengaruh melemahkan praktik adat. Beberapa sarana adat mulai ditinggalkan, seperti pakaian adat cawat saat kegiatan berdoa.

Kompleksitas masyarakat meningkat di tahun 1980an, terutama perbedaan etnisitas dan pilihan kegiatan ekonomi. Banyaknya migrasi dari luar Papua menjadikan masyarakat kurang memahami kelembagaan Sasi. Hal ini dapat meningkatkan resiko pelanggaran Sasi akibat ketidaktahuan ataupun penolakan. Realitasnya perbedaan identitas tidak berpengaruhi signifikan melemahkan pengelolaan, karena mayoritas pendatang dari luar Papua tidak bekerja di sektor perikanan tangkap, sehingga resiko pelanggaran dan penolakan menjadi rendah. Meningkatnya pilihan mata pencaharian sektor perkebunan, pertanian, pekerjaan formal, dan perikanan tidak menyurutkan semangat penerapan Sasi Laut oleh masyarakat, karena pada dasarnya Sasi Laut tidak mengganggu kegiatan sehari-hari masyarakat.

Pemerintah Kampung Folley yang diresmikan tahun 1991 turut berkontribusi menguatkan pengelolaan. Peran pemerintah menyetujui, ikut mengawasi dan menghubungkan dengan pemerintah pusat dan pembeli hasil, membantu mendorong kesuksesan praktik Sasi Laut. Disisi lain, perkembangan teknologi yang terintegrasi pengembangan desa membuka celah oknum untuk melanggar peraturan Sasi Laut, seperti mencuri 
hasil saat Tutup Sasi menggunakan alat bantu kompresor dan alat lainnya. Pelemahan pengelolaan ini diatasi masyarakat adat dengan menambah peraturan terkait sarana dan teknik panen ramah lingkungan.

Kepercayaan pemerintah pusat dan daerah kepada LSM TNC dalam mendampingi masyarakat berhasil menciptakan peleburan pengetahuan lokal dan ilmiah yang menguatkan pengelolaan Sasi Laut mulai tahun 2010. Sebagai contoh, pertimbangan jangka waktu Tutup Sasi sebelumnya mengikuti perhitungan musim atau kebutuhan mendesak masyarakat. Dekade terakhir, waktu Tutup dan Buka Sasi juga mempertimbangkan hasil produksi maksimal melalui proses monitoring rutin. Pelaksanaan monitoring juga bertujuan menangkap pelanggar/pencuri hasil, sehingga kegagalan Buka Sasi terminimalisir. Merujuk berkembangnya publikasi media massa inisiasi TNC, perlu dipertimbangkan terbukanya pengembangan wisata dan resiko komodifikasi budaya yang akhirnya dapat melemahkan nilai dasar pengelolaan Sasi Laut.

Pengakuan formal dari pemerintah melalui KKPD menjadi satu hal terpenting dalam menguatkan pengelolaan, karena; 1) meminimalisir resiko pengalihan fungsi wilayah atau perampasan hak ulayat masyarakat; 2) mendorong intervensi dukungan eksternal (TNC, pemerintah, UPT KKP) yang turut membantu mensukseskan pengeloloaan. Uraian diatas menunjukan perubahan unsur-unsur pengelolaan berpengaruh pada pelemahan atau penguatan pengelolaan. Tabel 3 menjelaskan dinamika pengelolaan secara komprehensif.

Tabel 3 Dinamika Pengelolaan Sasi Laut Kampung Folley, Distrik Misool Timur, Kabupaten Raja Ampat, Provinsi papua Barat.

\begin{tabular}{|c|c|c|c|c|}
\hline Momentum & $\begin{array}{c}\text { Faktor } \\
\text { Perubahan }\end{array}$ & Perubahan Unsur & Pelemahan & Penguatan \\
\hline $\begin{array}{l}1972 \\
\text { (pembangunan } \\
\text { kampung) }\end{array}$ & $\begin{array}{l}\text { Internal } \\
\text { - Sejarah } \\
\text { - Homogenitas } \\
\text { - Kepemimpinan dan } \\
\text { hukum adat } \\
\end{array}$ & $\begin{array}{l}\text { Murni pengetahuan } \\
\text { adat. }\end{array}$ & & $\begin{array}{l}\text { Hukum adat serta } \\
\text { kepemimpinan } \\
\text { mendorong Sasi }\end{array}$ \\
\hline $\begin{array}{l}1976 \\
\text { (Perkembangan } \\
\text { peranan Agama) }\end{array}$ & $\begin{array}{l}\text { Eksternal } \\
\text { - Kompleksitas } \\
\text { masyarakat }\end{array}$ & $\begin{array}{l}\text { Otoritas tokoh agama, } \\
\text { peraturan persepuluhan, } \\
\text { sanksi agama }\end{array}$ & $\begin{array}{l}\text { Sarana adat } \\
\text { sebagian } \\
\text { ditinggalkan }\end{array}$ & $\begin{array}{l}\text { Peran dan sanksi } \\
\text { agama memperkokoh } \\
\text { pengelolaan }\end{array}$ \\
\hline $\begin{array}{l}1980 \\
\text { (Perkawinan } \\
\text { antar etnik dan } \\
\text { migrasi) }\end{array}$ & $\begin{array}{l}\text { Internal } \\
\text { - Kompleksitas } \\
\text { Masyarakat (multi } \\
\text { etnik, agama dan } \\
\text { mata pencaharian) }\end{array}$ & $\begin{array}{l}\text { Peraturan } \\
\text { memperbolehkan } \\
\text { marga, agama dan etnik } \\
\text { lain memanfaatkan. }\end{array}$ & $\begin{array}{l}\text { Memungkinkan } \\
\text { resiko } \\
\text { pelanggaran Sasi }\end{array}$ & $\begin{array}{l}\text { Mayoritas pendatang } \\
\text { menghargai dan } \\
\text { mematuhi Sasi Laut. }\end{array}$ \\
\hline $\begin{array}{l}1991 \text { (Adms } \\
\text { Kamp. Folley, } \\
\text { introduksi } \\
\text { teknologi) }\end{array}$ & $\begin{array}{l}\text { Eksternal } \\
\text { - Dimensi regulatif } \\
\text { - Globalisasi } \\
\\
\text { (teknologi) } \\
\end{array}$ & $\begin{array}{l}\text { Otoritas pemerintah } \\
\text { kampung, peraturan alat } \\
\text { dan teknik memanen. }\end{array}$ & $\begin{array}{l}\text { Meningkatkan } \\
\text { resiko } \\
\text { pelanggaran Sasi } \\
\text { (alat merusak) }\end{array}$ & $\begin{array}{l}\text { Dukungan } \\
\text { Pemerintah, } \\
\text { Penggunaan API } \\
\text { ramah lingkungan. }\end{array}$ \\
\hline $\begin{array}{l}2001 \text { (intervensi } \\
\text { eksternal) }\end{array}$ & $\begin{array}{l}\text { Eksternal } \\
\text { - Intervensi pihak } \\
\text { TNC. }\end{array}$ & $\begin{array}{l}\text { Otoritas TNC, perluasan } \\
\text { wilayah, peraturan } \\
\text { waktu dan ukuran biota, } \\
\text { peningkatan } \\
\text { monitoring. }\end{array}$ & $\begin{array}{l}\text { Memungkinkan } \\
\text { keterbukaan } \\
\text { wisata dan } \\
\text { komodifikasi } \\
\text { budaya } \\
\end{array}$ & $\begin{array}{l}\text { Dukungan TNC } \\
\text { (bantuan sarana, } \\
\text { promosi, transfer IP } \\
\text { ilmiah, minim } \\
\text { pelanggaran) }\end{array}$ \\
\hline $\begin{array}{l}\text { 2006-2014 } \\
\text { Penetapan } \\
\text { KKPD }\end{array}$ & $\begin{array}{l}\text { Eksternal } \\
\text { - Dimensi regulatif } \\
\text { dan pengakuan } \\
\text { formal } \\
\text { - Intervensi pihak } \\
\text { UPT KKP. } \\
\end{array}$ & $\begin{array}{l}\text { Otoritas pihak } \\
\text { berwenang, monitoring } \\
\text { UPT KKP, sanksi (fisik, } \\
\text { ekonomi, formal), } \\
\text { pengakuan hak } \\
\text { Claimant. }\end{array}$ & & $\begin{array}{l}\text { Pengakuan hak adat } \\
\text { meminimalisir } \\
\text { pengalihfungsian } \\
\text { wilayah dan } \\
\text { pelanggaran Sasi } \\
\text { Laut. }\end{array}$ \\
\hline
\end{tabular}

Tabel 3 menunjukan proses perkembangan pengelolaan Sasi Laut Folley berpengaruh terhadap penguatan dan pelamahan pengelolaan, namun praktik sosial yang melemahkan tidak berpengaruh signifikan terhadap 
hasil produksi dan dapat diorganisir melalui revitalisasi unsur-unsur pengelolaan oleh masyarakat. Hasil penelitian menunjukan dinamika pengelolaan Sasi Laut Folley mengarah pada penguatan pengelolaan.

\section{SIMPULAN}

Pengelolaan Sasi laut Kampung Folley merupakan salah satu bentuk pengelolaan sumber daya berbasis masyarakat dan memuat enam unsur pengelolaan sumber daya berbasis masyarakat, yaitu memiliki batas wilayah yang jelas, hak kepemilikan untuk mengelola dan menentukan peruntukan wilayah, pemegang otoritas oleh tokoh adat, peraturan yang dibuat secara mandiri, sanksi yang berlaku, serta menjalankan monitoring dan evaluasi.

Terdapat lima periode masa yang mempengaruhi perkembangan pengelolaan Sasi Laut, terutama pada batas wilayah, hak, peraturan dan monitoring. Faktor yang melatarbelakangi adalah faktor internal sejarah pengelolaan Sasi dan homogenitas masyarakat Matbat, kekuatan pemimpin dan hukum adat, serta kompleksitas identitas dan ekonomi. Faktor eksternal yaitu regulasi Kawasan Konservasi, regulasi penetapan desa dan penyaluran program, intervensi peran stakeholders eksternal serta globalisasi melalui introduksi teknolog dan pendidikan. Perubahan dapat diorganisir dengan baik oleh masyarakat lokal dibantu peran multipihak, sehingga dinamika pengelolaan dapat menjadi input terhadap penguatan pengelolaan.

\section{UCAPAN TERIMA KASIH}

Ucapan terima kasih disampaikan kepada Kementerian Riset dan Teknologi / Badan Riset dan Inovasi Nasional Republik Indonesia atas sumbangan dana penelitian melalui beasiswa Program Magister menuju Doktor untuk Sarjana Unggul (PMDSU) berdasarkan Surat Keputusan Nomor 25/E/KPT/2018 dan Perjanjian / Kontrak Nomor 4393/IT3.11/PN/2018.

\section{DAFTAR PUSTAKA}

[BPS] Badan Pusat Statistik. 2017. Statistik Sumber Daya Laut dan Pesisir 2017. [diunduh pada 2018 Juli 20]. Tersedia pada: https://www.bps.go.id/publication/2017/12/21/c2451f58814e91d71124d541/statistiksumber-daya-laut-dan-pesisir-2017.html.

[BPS] Badan Pusat Statistik. 2018. Statistik Sumber Daya Laut dan Pesisir 2018. [diunduh pada 2018 Juli 20]. Tersedia pada: https://www.bps.go.id/publication/2018/12/07/93a0fd8885fe2ac14201e71a/statistiksumber-daya-laut-dan-pesisir-2018.html.

[KKP] Kementrian Kelautan dan Perikanan. 2015. Laporan Kinerja Kementrian Kelatan dan Perikanan. [diunduh pada 2018 Juli 20]. Tersedia pada: https://www.google.com/url?q=http://kkp.go.id/kategori/179LAKIP\%20KKP\&sa=U\&ved=0ahUKEwj q4L7nyNLaAhXCa7wKHdPmB_oQFggcMAE\&usg=AOvVaw0DhxO29wss1dJWBKpr1LgD.

[TNC] The Nature Conservancy. 2017. Implementasi "Sasi Laut" di Kampung Folley - Raja Ampat. Indonesia Coastal and Ocean Program Report. 17.

Alkausar A. 2011. Model Keterancaman Ritual Mappandesasi Dalam Masyarakat Nelayan Etnik Mandar Kelurahan Bungkutoko Sulawesi Tenggara [Tesis]. Denpasar (ID): Universitas Program Pascasarjana Universitas Udayana Denpasar.

Berkes F. 2000. Cross-Scale Institutional Linkages: Perspectives from the Bottom Up. IASCP. Conference Indiana University.

Bromley DW. 1992. Making The Commons Work. (Ed). San Francisco (CA): Institute for Contemporary Studies.

Cooley FL. 1987. Mimbar dan Tahta Hubungan Lembaga-Lembaga Keagamaan dan Pemerintahan di Maluku Tengah. Jakarta (ID): Pustaka Sinar Harapan. 
Creswell JW. 2016. Research Design Qualitative, Quantitative, and Mixed Methods Approaches. Fawaid A, Pancasari RK, penerjemah. Yogyakarta (ID): Pustaka Pelajar Yogyakarta.

Dahuri R. 2003. Keanekaragaman Hayati Laut. Aset Pembangunan Berkelanjutan Indonesia. Jakarta (ID): PT Gramedia Pustaka Utama.

Gorris P. 2016. Deconstructing the Reality of Community Based Management of Marine Resources in a Small Island Context in Indonesia.. Front. Mar. Sci. 3 (120): 1-15.

Horowitz LS. 2015. Local Environmental Knowledge dalam The Routledge Handbook of Political Ecology. Perreault T, Bridge G, McCarthy (ed). London (UK): Routledge.

Idrus M. 2009. Metode penelitian Ilmu Sosial. Yogyakarta (ID): PT. Gelora Akasara Pratama.

Khoirunisak, Satria A. 2016. Kelembagaan dan keberlanjutan eha laut dan mene'e sebagai model pengelolaan sumberdaya pesisir berbasis masyarakat di Desa Kakorotan, Kecamatan Nanusa, Kabupaten Kepulauan Talaud, Provinsi Sulawesi Utara. Sodality: Jurnal Sosiologi Pedesaan. 23-37.

Mongabay. 2015. Sasi, Konservasi berbasis Kearifan Lokal di Raja Ampat. [diunduh pada 2018 Januari 11]. Tersedia pada: http://www.mongabay.co.id/2015/07/12/sasi-konservasi-berbasis-kearifan-lokal-di-rajaampat/.

Mongabay. 2017. Terumbu Karang di Nusantara Membaik, Namun. [diunduh pada 2018 Februari 28]. https://www.mongabay.co.id/2017/07/17/terumbu-karang-di-nusantara-membaik-namun/.

Noviana L, Arifin HS, Adrianto L, Kholil. 2019. Studi ekosistem terumbu karang di Taman Nasional Kepulauan Seribu. Jurnal Pengelolaan Sumberdaya Alam dan Lingkungan. 9(2): 352-365. [Internet]. [diunduh pada 2019 November 23]. Tersedia pada: http://dx.doi.org/10.29244/jps1.9.2.352-365.

Ostrom E, Gardner R. Walker J. 1994. Rules, Games, and Common-Pool Resources. Ann Arbor (US): University of Michigan Press.

Ostrom E, Schlager E. 1996. The Formation of Property Rights in Hanna S, Folke C, Mäler KG. 1996. Rights to Nature: Ecological, Economic, Cultural, and Political Principles of Institutions for the Environment [Editor]. Washington DC (USA): Island Press.

Ostrom E. 1990. Governing the commons: the evolution of institutions for collective actions. Cambridge (US): Cambridge University Press.

Pical VJ. 2008. Pengaruh perubahan sistim pemerintahan desa terhadap pengelolaan sumber daya perikanan berbasis masyarakat di Pedesaan Maluku. Ichthyos. 7(2): 71-78.

Ruddel K. 1999. The role of lokal management and knowledge systems in small-scale fisheries. The Journal of Policy Studies. 7: 101-108.

Satria A. 2009. Pesisir dan Laut untuk Rakyat. Bogor (ID): IPB Press.

Soekanto S. 2002. Sosiologi: Suatu Pengantar. Jakarta (ID): Raja Persada.

Sugiyono. 2013. Metode Penelitian Kuantitatif Kualitatif dan R\&D. Bandung (ID): Alfabeta.

Sztompka P. 2004. Sosiologi Perubahan Sosial. Jakarta (ID): Prenada Media

Wahyuningsih SM, Angggoro S, Hartoko A. 2019. Evaluasi Efektifitas Pengawasan dalam Pengelolaan Kawasan Konservasi di Pulau Menjangan, Bali. Jurnal Pengelolaan Sumberdaya Alam dan Lingkungan. 9(2): 264-275. 